\title{
OPRESSOR VERSUS OPRIMIDO: O FEMINISMO DOS 99\% CONTRA O CAPITALISMO HEGEMÔNICO
}

\section{OPPRESSOR VERSUS OPPRESSED: 99\% FEMINISM \\ AGAINST HEGEMONIC CAPITALISM}

João Santos da Silva Júnior ${ }^{1}$

Resumo: Escrever um artigo capitalismo dentro da opressão com esse tema é uma tarefa her- feminista e de diferentes grupos cúlea, que não exige apenas força sociais como: negros, LGBTQ+, de vontade, mas entender os caminhos percorridos pelas mulheres e os movimentos feministas durante séculos, até o ápice contemporâneo, para tanto embasaremos os nossos pensamentos em diferentes estudos bibliográficos, contudo, principalmente mulheres e outros. O capitalismo e neoliberalismo que têm moldado as ações da sociedade democrática, rompendo com os direitos de grupos minoritários e subjugando as ações em defesa desses. Os manifestos feministas tendem a um anticapitalismo e o nas ideias do manifesto "femirompimento da fragmentação das nismo para os 99\%" de (Arruzza lutas, ou de representações ideaet al., 2019). Pretendemos aqui ria da meritocracia, que muito através de diferentes leituras é dissolvido na sociedade. Nos

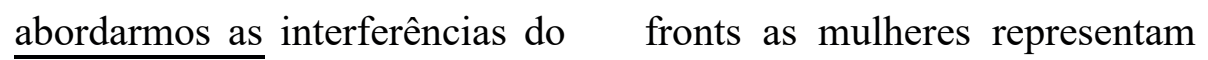
1 Professor da educação básica e Coordenador pedagógico; Formado em pedagogia e matemática; Pós-graduado em matemática e docência do ensino superior; Membro do grupo de pesquisa LEFOR, ligado a UNEB e ao Mestrado Profissional em Educação e Diversidade (MPED); Pesquisador de temas ligados ao feminismo, literatura brasileira e relações étnico-raciais

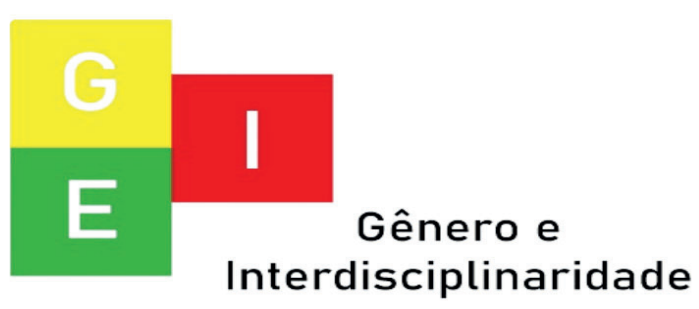


Vol. 02 - n 02 - ano 2021

a igualdade de diferentes classes e não apenas das mesmas, a defesa é embasada em tudo aquilo que o capitalismo interfere com as suas ações corrosivas, que superficialmente representa o desenvolvimento, contudo, por traz escraviza os menos favorecidos e inerentes ao ciclo desenvolvimentista que favorece pequenos grupos capitalistas.

Palavra-Chave: Feminismo, Anticapitalismo, Antineoliberalismo e Feminismo para os 99\%.

Abstract: Writing an article with this theme is a herculean task, which requires not only strength, more to understand the paths taken by women and feminist movements for centuries, up to the contemporary apex, to support our thoughts in different bibliographic studies, but mainly on the ideas of the manifesto "fe- minism for the $99 \%$ " of (Arruzza et al., 2019). We intend here through different readings to address the interferences of capitalism within feminist oppression and different social groups such as: blacks, LGBTQ+, women and others. Capitalism and neoliberalism that have shaped the actions of democratic society, breaking with the rights of minority groups and subjugating actions in defense of these. Feminist manifestos tend to an anticapitalism and the disruption of the fragmentation of struggles, or idealistic representations of meritocracy, which is much dissolved in society. On the fronts women represent the equality of different classes and not only of women, defense is based on everything that capitalism interferes with its corrosive actions, which superficially represents development, but which behind it enslaves the

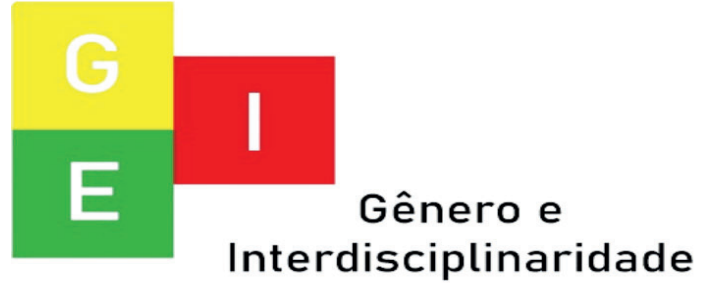


Vol. 02 - n 02 - ano 2021

Editora Acadêmica Periodicojs

less favored and inherent in the development cycle that favors small capitalist groups.

Keyword: Feminism, Anticapitalism, Anti-Neoliberalism and Feminism for the $99 \%$.

O FEMINISMO ATICAPITALISTA E ANTINELOLIBERAL

O conservadorismo que vem se perpetuando ao longo dos anos e atacando os desejos e anseios das mulheres encontra base fecunda no capitalismo neoliberal, onde a maximização do lucro tende a estabelecer à permanência de forma versátil as ações que interferem na luta feminina contra a hegemonia de um ideário permanente do capitalista explorador, que autodetermina ou inviabiliza as ações anticapitalistas e antineoliberais.
As lutas em prol das

mulheres desenvolvidas ao longo dos anos não buscaram apenas pela ocupação superficial do direito de ser e estar em sociedade, de forma não apenas igualitária, mas que despendesse no objetivo da busca pelo respeito. Se aprofundarmos a ideia em termos de neoliberalismo, entendemos que houve um avanço notório na privatização e cortes em políticas públicas sócias, isso possibilitou que a mulher exercesse um grau maior de responsabilidade, além de lidar com as cargas horárias de trabalhos exaustivas, cujo capital pago por essa mão de obra seja abaixo das dos homens, ainda precisa lidar com o trabalho doméstico atendendo todos aqueles que as cercam. Essa escravização feminina construída pelo capitalismo tende a permanecer na sociedade desde que haja uma luta engajada voltada a represen-

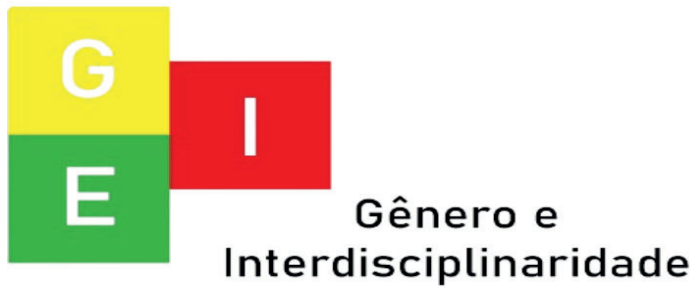


ISSN: 2675-7451

Vol. 02 - n 02 - ano 2021

Editora Acadêmica Periodicojs

tatividade de um total, e não de uma pequena parcela, como afirma (Arruzza et al,.2019) em seu manifesto.

As lutas feministas não visa apenas atacar o capitalismo ou aos lucros por ele gerando, as ações elas diversificam para além do trabalho, para a autora essa luta está presente em outros ambientes, "em diversos terrenos sociais e não apenas por meio de sindicatos e organizações oficiais de trabalhadores", incluindo as lutas "por sistema de saúde universal e educação gratuita, por justiça ambiental e acesso à energia limpa, por habitação e transporte público". ( et al, 2019, p. 55). As mulheres são as responsáveis por estar no front das lutas de classe, sendo elas as maiores vítimas do capitalismo voraz, são elas também as protagonistas das mobilizações sociais e de reprodução, essa reprodução que a teoria marxista tanto evidência na perspectiva de que o capitalismo explora as mulheres como reprodutoras responsáveis pela geração de novos sujeitos que servirão de mão de obra para o mesmo.

No seio da sociedade contemporânea os desafios se fazem cada vez mais presentes e desestruturastes. As ideias patriarcais mobilizadas por séculos tendem a permanecer, dado as imposições do capitalismo. As lutas feministas que aconteceram embasando a ideia de resistência a um sistema que deprecia, escraviza, monopoliza e invizibiliza a mulher. Movimentos de resistência como: "Ni una a menos" que aconteceu na Argentina em 2016 e acabou chegando ao Brasil e "Women's March", que foi a marcha de mulheres contra o então governo do Presidente Donald Trump nos Estados Unidos, isso

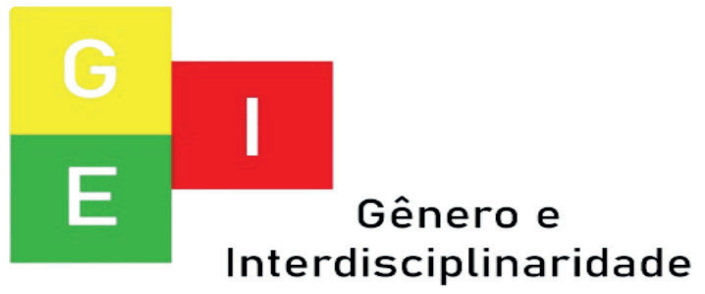


ISSN: 2675-7451

Vol. 02 - n 02 - ano 2021

Editora Acadêmica Periodicojs

em 2017. Todos esses movimentos tiveram como base a marcha das mulheres "Huelga Feminista" que movimentou milhões de mulheres em diferentes partes do planeta. As ideias defendidas pelo movimento encontravam base no marxismo, no manifesto Marx e Engel, Para (Arruzza et al., 2019)

Mas é acima de tudo a greve que constitui a novidade mais importante da nova onda. Não só porque a greve colocou no centro do debate o trabalho das mulheres, o papel das mulheres na reprodução social e a relação entre produção de mercadorias e reprodução, mas porque se tornou o motor principal de um processo de subjetivação através do qual uma nova subjetividade feminista anticapitalista está emergindo. (ARRUZZA, 2019 p, 12).

O movimento de 2017 no EUA ganhou espaço também no Brasil, quando o sindicato dos Professores do Ensino Oficial do Estado de São Paulo (APEOESP) ,que é considerando um dos maiores da América Latina e representante da educação básica de São Paulo entrou na luta. O movimento aderiu ao protesto em 08 de março de 2017 e convocou a paralização geral. A convocação feita pela maioria feminina, não uniu apenas as mulheres, mas diferentes indivíduos sociais, de acordo com o boletim da APEOESP:

Mulheres e homens protestaram em todo o planeta contra a ascensão de uma ideologia que desrespeita não apenas o

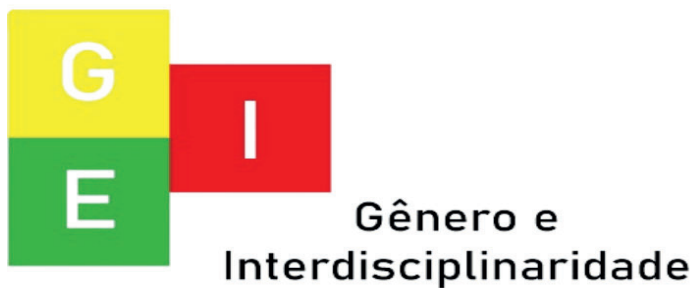


ISSN: 2675-7451

Vol. 02 - n 02 - ano 2021

Editora Acadêmica Periodicojs

sexo feminino, mas também os direitos dos imigrantes e da população LGBT. (...) Os direitos femininos envolvem todos, independente de gênero, raça e classe social, como demonstraram os milhares de manifestantes reunidos nas Marchas de Mulheres. (APEOESP, 2017)

Essa luta tomou como principio as questões de negação e racismo do governo do EUA e visões governamentais no Brasil, que tinha ideologias, que ia de encontro aos direitos das mulheres e de classes menos favorecidas como: negros, LGBT e outros.

Até aqui abordamos um feminismo centrado em uma visão mundial, de onde parte os anseios sociais de diferentes grupos agregados a uma luta de classe que representa a grande maioria marginalizada. No Brasil essa luta não se faz diferente ou menos importante, desde os primórdios as classes inferiores lutam por liberdade por representatividade e respeito, a nossa particularidade histórica nos remete a um passado de lutas e hoje a uma herança sombria permeada pelos resquícios escravistas e de subordinação, isso incluído todo processo de consolidação do capitalismo. Nesse caminho o processo de construção de uma sociedade assalariada não fez com que se rompesse a racialização e até mesmo os estigmas voltados às classes menos favorecidas. $\mathrm{O}$ processo do capitalismo, só fez se construir uma barreira cada vez maior dentro das classes sociais, onde o assalariado estaria a serviço do desenvolvimento de uma minoria, sendo que a única valorização do trabalhador seria a sua mão de obra a baixo custo.

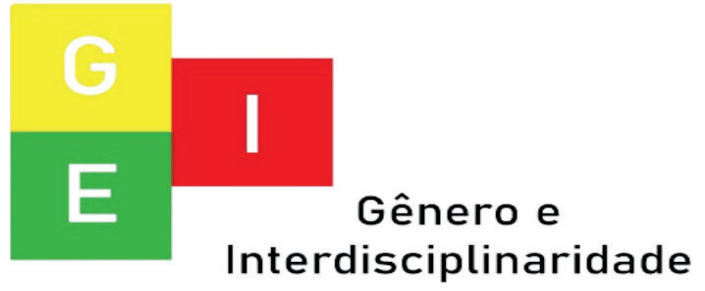


ISSN: 2675-7451

Vol. 02 - n 02 - ano 2021

Editora Acadêmica Periodicojs

Devemos lembrar aqui que dentro das imposições do capitalismo as questões de gênero dentro de uma sociedade patriarcal eram tão absurdas quanto às do negro, essas questões envolviam a vinculação da mulher à família, onde a mesma estava em função do trabalho doméstico/ familiar, ou com baixos salários colocando-as a margem do poder econômico e político, o que de certa forma controlava a força feminina.

Esse pequeno olhar sobre a formação das relações entre capitalismo e a sociedade brasileira define saber que ao subjugamento e opressão, não são temas contemporâneos, mas que o despertar conciso para a ocupação do front das lutas pelas mulheres, estão cada vez mais incisivos e presentes no nosso dia a dia, para (Samora Machel, 1976) ela entende que a mulher sempre foi o ser mais humilhado e explorado:

De uma maneira geral, no seio da sociedade, ela [a mulher] aparece como o ser mais oprimido, mais humilhado, mais explorado. Ela é explorada, até pelo explorado, batida pelo homem rasgado pela palmatória, humilhada pelo homem esmagado pela bota do patrão e do colono (MACHEL, 1976, p. 18).

Por tanto vencer o opressor só com aluta dos oprimidos, e nesse sentido a mobilização feminina toma frente das maiores demandas sociais, impostas pela visão parcialista de um neoliberalismo, que maquia as verdadeiras intenções e ações do capitalismo antissocial.

As lutas feministas que iniciam no século XIX e se in-

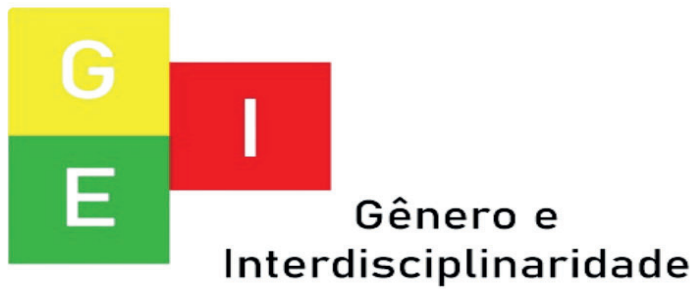


ISSN: 2675-7451

Vol. 02 - n 02 - ano 2021

Editora Acadêmica Periodicojs

tensificaram a partir do final do século XX, estrutura diferentes pensamentos correlacionados com o abatimento de ideias retrogrades que minimizavam o papel da mulher na sociedade e as libertavam de um escravismo velado, dado que para além das funções assalariadas, as mulheres ainda teria que cuidar da casa e estar a serviço do opressor doméstico que seria o homem, essas lutas como bem afirma (González, 2010) abre caminho para questionar seus direitos dentro da sociedade, de acordo com a autora:

Lutando juntas, as mulheres tinham mais possibilidades de êxito na hora de defender seus interesses do que se lutassem separadas. Além disso, as mulheres entendiam melhor os problemas e as demandas das outras companheiras (...) sentiam-se mais livres para se expressarem e darem suas opiniões no meio de outras mulheres, livres dos preconceitos (GONZÁLEZ, 2010, p. 65).

Nesse sentido que os questionamentos passam a ganhar espaço e apoio, fomentando uma luta defensiva em prol de um todo como bem afirma (Arruzza, et al.,2019) em seu manifesto, “Feminismo para os 99\%”, o qual abordará no tópico posterior. As bandeiras levantadas nos movimentos serviam como escudo e passo para a liberdade, a inexorável proposta das feministas tendiam a representatividade coletiva, e na concatenação com outros grupos marginalizados, fundava-se com objetivo concreto a busca por dias melhores, sendo que os mais diferentes grupos sofreram/

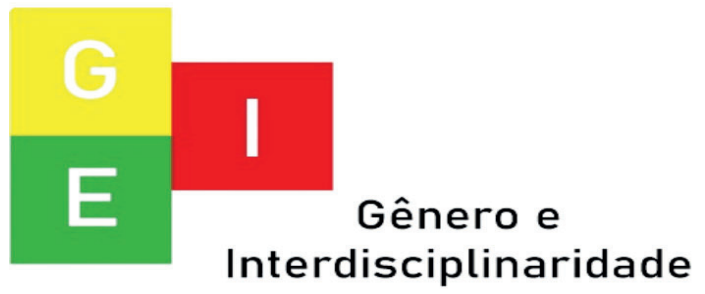


ISSN: 2675-7451

Vol. 02 - n 02 - ano 2021

Editora Acadêmica Periodicojs

sofrem a marginalização e exclusão como afirma (Martuscelli, 2020):

A sobreposição e intersecção de identidades sociais e dos sistemas relacionados de opressão, dominação, discriminação, injustiça social e desigualdade - que se expressam no racismo, sexismo, xenofobia, homofobia, transfobia etc. - não se apresentam num vácuo histórico. (MARTUSCELLI, 2020, p'80)

$\mathrm{O}$ que quer dizer que, todos os problemas de dominação opressão não são atuais, mas construídos ao logo da história com forte influência do capitalismo segregador e de ideias liberais que fascina superficialmente o olhar do individuo, mas que corrói de forma velada e estra- tégica as relações e correlações existentes entre grupos sociais, nesse momento que a traça, do neoliberalismo destrói tudo de forma discreta, porem com o tempo chega a torna e as vozes precisam ser ouvidas e as ações respeitas e a luta planejada com o objetivo de dissipar as traças do neoliberalismo, por tanto para que haja o rompimento das corretes opressoras capitalistas é fundamental que a luta pela emancipação feminina seja pontual e que agregue o maior numero possível de seguidores, as ideias marxista pulsam nas vozes dessa mulheres e que a radicalidade seja elemento fundamental nas demandas das lutas como bem afirma (Valadares, 2016)

Do ponto de vista marxista sobre a questão do gênero, surge o feminismo emancipacionista,

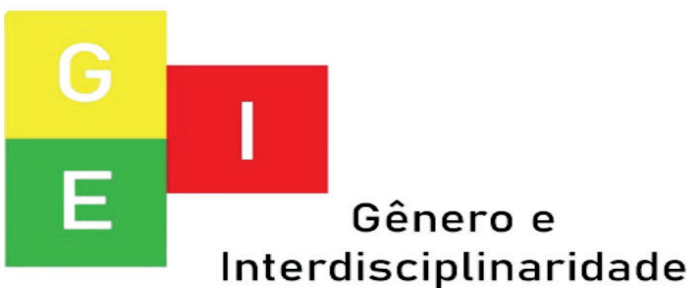


ISSN: 2675-7451

Vol. 02 - n 02 - ano 2021

Editora Acadêmica Periodicojs

que visa a tão somente puxar o fio da radicalidade até $o$ patamar da transformação da sociedade e continuar puxando até o processo de construção de uma nova, em todas as suas etapas, enquanto persistir a força estrutural/cultural [ou dominação-exploração] da opressão de gênero (VALADARES apud SCHAEFFER, 2016).

No Brasil e no mudo as relações de dependência ainda fazem parte do dia a dia, porem essa dependência tem dado espaço para o ( in) que contesta a opressão e o subjugamento, as lutas os anseios despertam do olhar de cada ser marginalizado a vontade de buscar seus direitas e defender o seu espaço, as lutas femininas são espaços que agregam os diferentes grupos, cons- trói sentidos de compartilhamento de força e de objetivos como bem afirma (Saffioti, 2015)

O feminismo traz, em seu bojo, um potencial crítico capaz de apontar caminhos, trilhas, picadas para se atingir o alvo expresso e desejado (...) isto não basta; é preciso saber utilizá-lo, selecionando as melhores estratégias em cada momento (...) o objetivo das (os) feministas consiste em transformar a sociedade, eliminando as desigualdades, as injustiças, as iniquidades, e instaurando a igualdade. (...). (SAFFIOTI, 2015, pág., 10)

\section{O FEMINISMO QUE RE-} PRESENTA OS 99\%

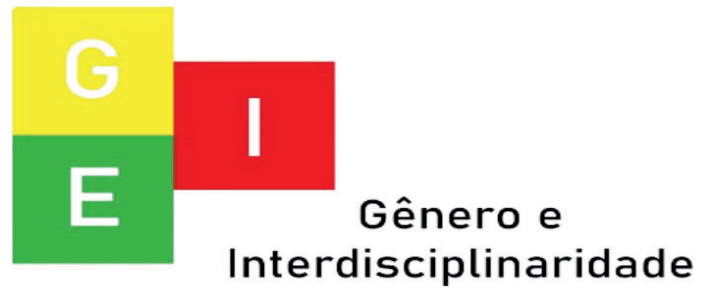


Vol. 02 - n 02 - ano 2021

Editora Acadêmica Periodicojs

Os movimentos femi- ca a imagem das mulheres como

nistas que desabrocham na sociedade, com intensificação a partir de manifestos que se distribuiriam pelo mundo como o "Manifesto feminista", busca despertar os olhares para os mias diferentes grupos invizibilizados pela sociedade e achatados pelo capitalismo que se mutua a partir do contexto em que é exposto. Não só um movimento centrado em torno da uma luta anticapitalista como também a pregação de uma visão neoliberal, que destrói a maioria e torna a sua força e luta como algo improprio e sem a devida necessidade de existência.

No livro Feminismo para os 99\%: um manifesto lançado em edição brasileira pela editora Boitempo no ano de 2019, nos traz uma ideia exata do que o movimento feminista deva lutar contras as hegemonias arraigada na sociedade onde personifi- seres submissos e dependentes do homem, nesse contexto não apenas as mulheres são inviabilizadas como diferentes grupos sociais que vivem a margem da sociedade ou são lá colocados por visões e ações estereotipadas que depreciam o ser humano.

As autoras Cinzia Arruzza, uma das grandes feminista italiana, professora da New School of Social Research de Nova Iorque e autora do livro Marxismo e feminismo: Entre Casamentos e divórcios é uma das mais ferrenhas apoiadoras da greve internacional das mulheres nos Estados Unidos. Tithi Bhattacharya é professora associada de história do sul da Ásia na Purdue University, é uma feminista marxista de destaque e uma das organizadoras da greve internacional das mulheres e Nancy Fraser é filósofa, titular da cátedra Henry

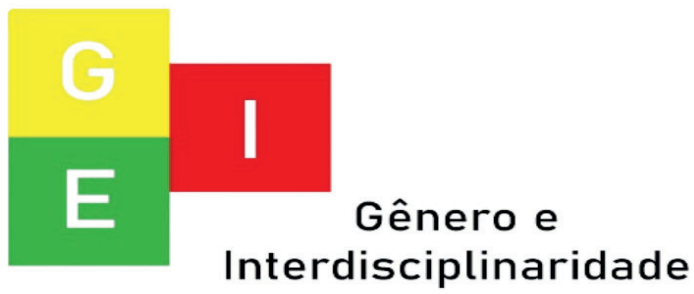


ISSN: 2675-7451

Vol. 02 - n 02 - ano 2021

Editora Acadêmica Periodicojs

A. and Louise Loeb de Ciências Políticas e Sociais da New School University, em Nova Iorque e, autora de obras como Fortunes of feminism, Feminist contentions, entre várias outras traduz o conceito mais amplo e que agreva os delenimantos produtivos dos movimentos e para que os mesmos devam acontecer.

A ideia das autoras nos traz uma visão de que forma esta se construído socialmente uma visão minoritária do feminismo, onde as lutas de classes tem dado espaço, ou por vezes sofrido, com realidade superficial, onde poucos constroem a visão do coletivo. O que se entende nessa perspectiva e de acordo com o manifesto feminista é que as poucas figuras femininas que estão em cargos do alto escalão, têm defendido de forma genérica que as mulheres estão sendo representado socialmente, esse projeto de edificação de uma imagem igualitária sofrem impactos quando se observa que mesmo sendo um cargo de chefia a mulher estará subjugada por uma figura masculina em um cargo superior.

A "encruzilhada" da qual as autoras reforçam o seu manifesto está justamente em entender que mesmo as mulheres estando ocupando cargo de chefia, isso só representa $1 \%$ do total, que por tanto os $99 \%$ ainda estão em uma sociedade que as vê com indivíduos inferiores, isso principalmente quando parte de uma visão masculina. O que se torna evidente nesse emaranhado de negações, subjugamentos, restrições, invisibilidade entre vários outros conceitos, é que o capitalismo é o regente dessas situações como bem afirma as autoras.

O processo que se constrói em torno da figura feminina

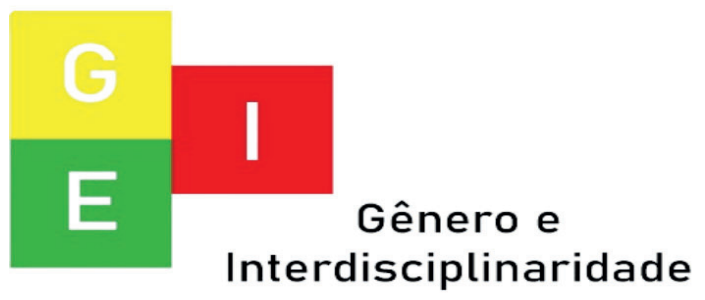


ISSN: 2675-7451

Vol. 02 - n 02 - ano 2021

Editora Acadêmica Periodicojs

e dos diferentes grupos inviabilizados como: negros, gays, ciganos, pobres entre outros é que se há uma ótica construída dentro de duas vertentes opostas, onde de um lado o capitalismo seria a base da igualdade nesse sentido a concepção de ascensão feminina e reconhecimento possibilitaria equiparação social que encontraria lugar dentro da cadeia econômica. Na outra vertente estão os grupos de mulheres que veem o capitalismo como o grande empecilho para a conquista de um feminismo para todos.

As ideias embasadas nessa ultima vertente é característico do feminismo defendido pelas organizadoras da marcha "Huelga Feminista", que acreditam que a liberdade e a igualdade sejam premissas de um novo mundo. Esse ideário está centrado principalmente no papel do genro no desenvolvimento do ca- pital, embora as mulheres sejam seres ativos e que desenvolvem um trabalho indispensável na e para a sociedade, não há nenhum tipo de recompensa por isso, nessa perspectiva o ativismo feminino defendido na marcha encontra um terreno fértil de discussões, considerando não só questões trabalhistas como entendendo que não existe apenas a concentração de salario, mas entendendo que as mulheres também são vitimas de assédios, agressões sexuais invisibilidade no trabalho, visões preconceituosas, que por vezes determinou o papel e o lugar da mulher dentro da sociedade.

O surgimento dos movimentos feministas tende a representar os anseios das mulheres outras classes subjugadas e inferiorizadas. A ideia que existe um feminismo liberal onde acredita-se que as mulheres possam

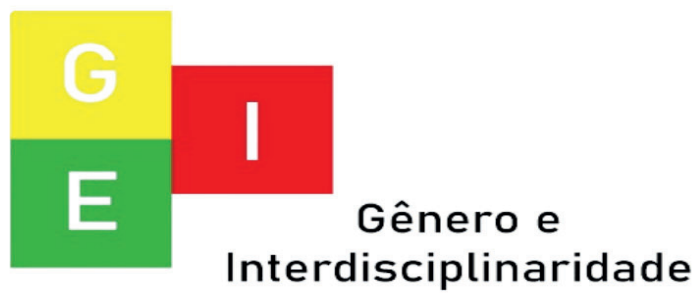


ISSN: 2675-7451

Vol. 02 - n 02 - ano 2021

Editora Acadêmica Periodicojs

alcançar seus espaços através de suas ações e capacidades está dando espaço a uma nova visão de feminismo, abolindo e desmistificando essa imposição de ideário igualitário em prol de um novo feminismo que impulsione os ajustes estruturais e não sirva de preceito para ocultar o neoliberalismo e que apoiam politicas regressivas sob a "ótica" de emancipação.

Os movimentos feministas regram-se pela procura de uma luta anticapitalista e ao tempo que favoreça não apenas $1 \%$ das mulheres, mais sim a grande maioria massiva, que enfrentam desafios diários dentro da sociedade. As lutas que buscam representar os $99 \%$, como bem afirma as autoras o feminismo deve ter por objetivo "atracar as raízes capitalistas da barbárie metastática” (pág. 41). Nessa perspectiva o feminismo busca não sacrificar o direito e o bem-estar desses 99\% em favor de uma minoria, de uma liberdade que não representa a totalidade, e que esconde através das arestas do tempo uma perpetuação preconceituosa de ações em desfavor dos menos favorecidos.

A liberdade e a proteção estarão ameaçadas pelo neoliberalismo assim acredita as autoras, pois o mesmo remodela a opressão de gênero, no entanto a liberdade dessa opressão dar-se-á pela ocupação de seu espaço e lugar de fala feminina alinhado em conformidade com a defesa de gênero transformado o sistema social subjacente onde os direitos das mulheres são ocultados. A opressão dos direitos dos mesmos favorecidos está sob a direção do capitalismo, que determina de que forma os sujeitos podem viver em sociedade. A crise que o capitalismo origina não está ape-

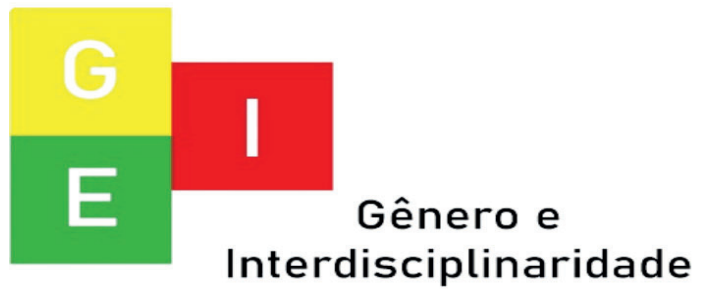


ISSN: 2675-7451

Vol. 02 - n 02 - ano 2021

Editora Acadêmica Periodicojs

nas na exploração do trabalho assalariado, mas tombem nas consequências da sua exploração dos sujeitos da sociedade, na opressão de gênero na discriminação e por vezes na subordinação da reprodução social que visa o lucro. O capitalismo depende da mulher para a produção de mão de obras, ou seja, como reprodutora natural da vida, a mulher está subordinada ao capital, tendo ela o papel vital da reprodução social, o que de fato é ocultado em nossa sociedade. Não apenas a força feminina é explorada pelo capital como também o "dom de conceber a vida".

Nesse enredo em que o capitalismo determina a ação dos sujeitos na sociedade, oprime os menos favorecidos, e os diferentes grupos sociais, ele também busca regular a sexualidade dentro da sociedade, esse tipo de violência é um dos enfrentamen- tos do feminismo para os $99 \%$. O mercado de trabalho buscou ao longo dos tempos construir imagens distantes da realidade, os sujeitos estão expostos a regras de condutas dentro do espaço de trabalho, de acordo com as autoras havia restrições com relação a opção sexual e exposição no espaço de trabalho, tudo isso para beneficiar a ordem capitalista, com o tempo na busca por manter o ganho capital vendendo as imagens de pessoas que vivam fora das famílias heterossexuais, como afirma as autoras "Na sociedade capitalista, o sexo vendee o liberalismo o comercializa em muitos sabores"(pág. 70).

Os entrelaçamentos entre o capitalismo, o racismo, a luta de classe a homofobia, a destruição da terra, preconceito entre outras opressões, estão enraizados dentro da sociedade. A visão feminista determina que

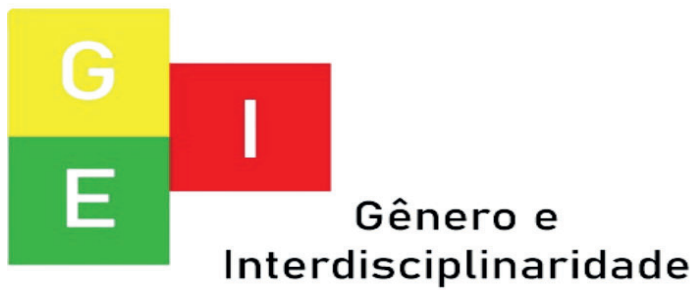


ISSN: 2675-7451

Vol. 02 - n 02 - ano 2021

Editora Acadêmica Periodicojs

os vários processos que tende a inviabilizar os grupos menores possuem raízes fecundas no capitalismo e nas ideias neoliberais, que estruturam visões igualitárias distantes da realidade. A produção de caminhos para reverter essa situações encontram caminhos fecundos nas lutas feministas, mas não apenas em um representação superficial que busque sequestrar o direito de fala da maioria em detrimento de uma maioria, que estando ocupando os cargos de chefia nas grandes empresas, não fazem nada em favor das minorias, isso por que o capital determina as ações desses sujeitos. Mesmo que as mulheres estejam ocupando as multinacionais, sempre estarão submissas ao capital, por tanto esse $1 \%$ das mulheres ocupando os altos escalões não representam os $99 \%$ que compreende todas as classe minoritárias em direitos mas majoritárias em tamanho.

A alienação social orquestrada pelo capitalismo define as ações até que haja uma subversão de valores na luta pela igualdade da maioria. O manifesto comunista de Marx e Engel 1848, já preconizava a ação dos sujeitos, unificando as forças nas lutas, intencionalizando as mesmas na tentativa de um dia abolir o capitalismo, para só então a igualdade e equiparidade fazer parte da nova ordem social. Essa unificação não será apenas de mulheres, mas também de diferentes grupos sociais como: negros, LGBTQI+, mulheres, índios, judeus e outros grupos que se veem marginalizados pelo capital voraz, que permeia a sociedade.

O feminismo para os $99 \%$ traduz os anseios sociais de igualdade, direito e respeito às mulheres frente às demandas de uma realidade opressora, que jul-

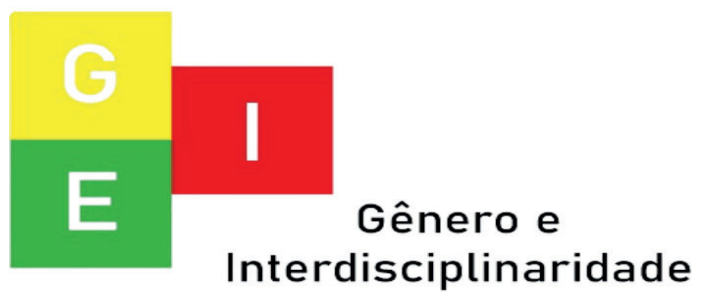


ISSN: 2675-7451

Vol. 02 - n 02 - ano 2021

Editora Acadêmica Periodicojs

ga e determina os caminhos que as mulheres tendem a tomar, em face de uma estrutura capitalista que coopta grande parcela da população onde essas mulheres estejam a serviço de uma estrutura, racista, sexista, preconceituosa, elitista e segregacionista que inibe o poder dos menos favorecidos e subjugam os direitos e ações desenvolvidas por aqueles que buscam sobressair de situações socialmente inferiores. Os resultados das lutas revelam e ao mesmo tempo aproxima os diferentes sujeitos da realidade vivida pelas mulheres em senário social dentro ou não do campo de lutas feministas, mas também das relações existentes entre essa luta e as classes necessitadas de representação, que sofrem momentaneamente com o racismo, a discriminação, a xenofobia entre outras formas de preconceito, inviabilizam o ser humano, ou cer- to grupo da sociedade brasileira.

O campo da luta e de embates feministas está centrado na capacidade de mudança que os movimentos organizados podem propiciar no interior da sociedade e na tentativa de resolução de problemas, essa é a grande bandeira defendida pelas autoras do manifesto. Não existe um caminho fácil e emancipatório ao mesmo tempo, diante do poder opressor do neoliberalismo e do capitalismo, como produtores dos mais diferentes desastres sociais que atingem as parcelas da sociedade que não se "adequam" à corrosividade do capitalismo. Por isso a luta por uma sociedade anticapitalista. O feminismo para os $99 \%$ é um manifesto que tem como ponto central das discussões o fato de que o direito de parte da população é despojado em benefício de uma minoria de $1 \%$, que não representa os $99 \%$.

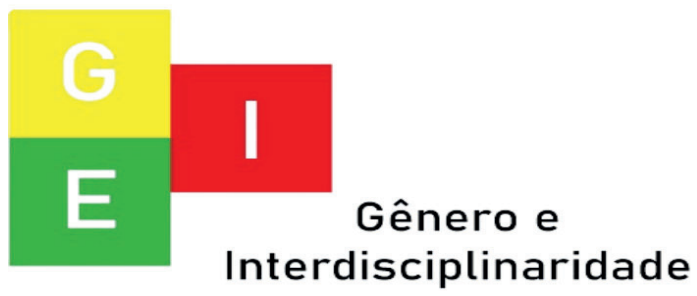


ISSN: 2675-7451

Vol. 02 - n 02 - ano 2021

Editora Acadêmica Periodicojs

A mudança necessária está principalmente porque o $1 \%$ que alcança o âmago do capitalismo, não busca reverter a lógica imprópria das estruturas arraigadas na sociedade em benefício dos 99\%. A insurgência dos grupos invisibilizados seria, na perspectiva das autoras, o caminho da mudança, assim como a construção de uma ótica anticapitalista. As ideias descritas pelas autoras do livro se entrelaçam com a visão das autoras (Faria e Moreno, 2017), que definem que o capitalismo assim como o racismo e o patriarcado formam modelos de múltiplas dominações, tornando-se violentos nos seus mecanismos de acumulação. A reversão de ideia onde a mulher é vista pela sociedade machista, não como um ser social, mas por várias vezes um produto ou objeto a serviço de algo ou alguém, pode ser um caminho para repensar o papel e importância da mulher na/para a sociedade Nessa linha de pensamento a autora (D'alessandro, 2016) defende uma sociedade igualitária, e evidencia a opressão que as mulheres sofrem diariamente dentro do processo capitalista destrutivo.

O "feminismo para 99\%" é uma obra que traz discussões, que perpassam o simples questionamento e evidenciam a imersão em um vasto e rico campo de luta, na busca por valorização e respeito. $\mathrm{O}$ feminismo defendido pelas autoras não abrange apenas a luta das mulheres, mas também a de todos os grupos inviabilizados pela sociedade, que sofrem com a falta de direitos, igualdade e respeito. As lutas feministas da atualidade de acordo com (Arruzza, 2017) é considerada um dos caminhos valorativos para as lutas de classes e representa os anseios femi-

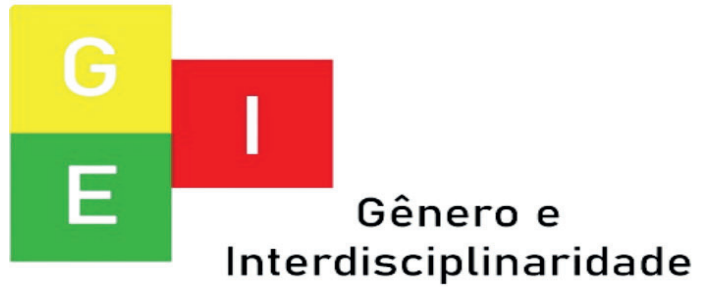


nistas frente à construção de uma nova sociedade, tornando-se algo emancipatória e libertador, e visa à construção de ideias anticapitalistas para a compreensão social e plural que represente um todo de uma sociedade.

\section{CONCLUSÃO}

Ao mesmo tempo em que pensamos fechar esse trabalho, chegamos à conclusão de que não há uma conclusão, dada as inquietações emergentes das discussões diárias, das lutas e embates que os diferentes grupos liderados ou não por mulheres vem travando contra o capitalismo opressor e um neoliberalismo fascista. O ponto central é que, se concluímos as nossas ideias, e fechamos nossos pensamentos, estaremos rompendo com a ideologia de luta de enfrentamento das diversidades que a sociedade vive contemporaneamente. Não é um processo estanque, neutro ou passivo, a luta feminista que tende a representação dos 99\%, não busca apenas vencer as barreiras autoritárias e dominantes do capitalismo, mas dar voz a um sem número de pessoas, que sofrem diariamente com a opressão, racismo, xenofobia, preconceitos das mais diferentes estruturas.

O feminismo representativo embasado pelas ideias marxistas e manifestado na marcha das mulheres que acontece em todo mundo desde o ano 2000, não é uma luta visionária para chegar ao poder, mas pelo respeito e igualdade entre homens e mulheres, o respeito para todos os grupos marginalizados como negros, LGBTQ+ e outros. A luta ela contrapõe a ideia do neoliberalismo e os princípios políticos que o capital sustenta atualmente, buscando romper as alianças existentes entre o neoliberalismo

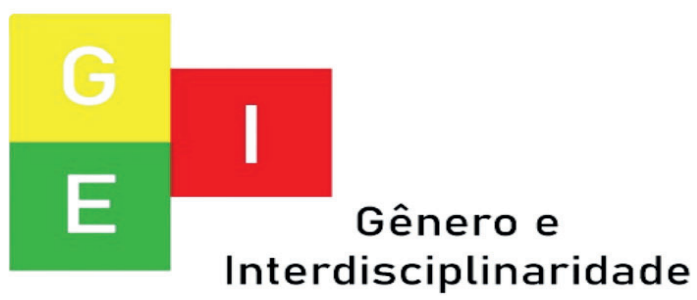


ISSN: 2675-7451

Vol. 02 - n 02 - ano 2021

Editora Acadêmica Periodicojs

progressista e as forças femininas do Faça Acontecer, centrados na ideia que tudo depende da mulher, onde o capitalismo não interfere na posição em que a mesma ocupa na sociedade.

As lutas feministas são oportunidades de colocar no auge desejos e anseios de diferentes grupos sociais que sofrem com as imposições desastrosas do capitalista e suas raízes meritocratas como o neoliberalismo e uma democracia, que está a serviço do capital e não do social. A capacidade norteadora das ações feministas determina a construção de ideais alicerçadas no direito celebrado diariamente de conquistas, capitando diferentes grupos em prol de uma causa de liberdade, junto a uma visão anticapitalista, antineoliberalista e antirracista. A primazia dos movimentos feministas é promover um revolte contra as forças opressoras, é destacar o lugar de fala das mulheres, constituindo-as como protagonistas do seu futuro, por tanto precisa ser uma luta diária, vencendo as amarras do capitalismo.

\section{REFERÊNCIAS}

APEOESP Notícias - Assembleia estadual 8 de março. Publicado em 03/03/2017.

Disponível em: http://www. apeoesp.org.br/noticias/noticias-2017/assembleia-estadual8-de-marco-quarta-14h30-vao-livre-do-masp/ Acesso em 22 mai. 2021.

ARRUZZA, C.; Bhattacharya, T.; Fraser, N. Feminismo para os 99\%: um manifesto. São Paulo: Boitempo, 2019.

D'ALESSANDRO, Mercedes. Economía feminista: Cómo criar una sociedad igualitária ( $\sin$ perder el glamour). Espanha: Suda-

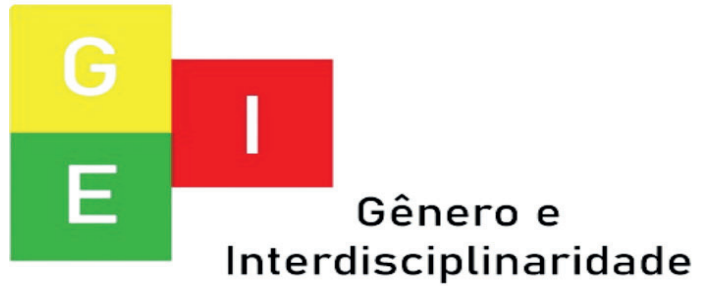


mericana, 2016.

FARIA, Nalu; MORENO, Rena-

ta. Desafios para enfrentar o conflito do capital contra a vida: Nós mulheres seguimos em luta! São Paulo: SOF, 2017.

GONZÁLEZ, Ana Isabel Álvarez. As origens e comemoração do Dia Internacional das Mulheres. São Paulo, Expressão Popular; SOF: Sempreviva Organização Feminista, 2010.

MARTUSCELLI, Danilo Enrico (org.) Os desafios do feminismo marxista na atualidade / Danilo Enrico Martuscelli (org.) - 1. ed. - Chapecó, Coleção marxismo21, 2020.

SAFFIOTI, Heleieth. Gênero, Patriarcado, Violência. São Paulo, Expressão Popular, 2015.

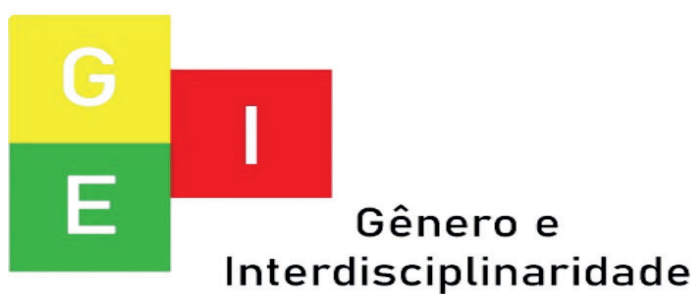

